Article

\title{
Peroxynitrite-Mediated Dimerization of 3-Nitrotyrosine: Unique Chemistry along the Spectrum of Peroxynitrite-Mediated Nitration of Tyrosine
}

\author{
Tara R. deBoer ${ }^{1}$, Rafael I. Palomino ${ }^{2}$, Pradip K. Mascharak ${ }^{2, *}$ \\ 1 Department of Bioengineering, College of Engineering, University of California, \\ Berkeley, CA 94720, USA \\ 2 Department of Chemistry and Biochemistry, University of California, Santa \\ Cruz, CA 95064, USA \\ * Correspondence: Pradip K. Mascharak, Email: pradip@ucsc.edu.
}

\begin{abstract}
Peroxynitrite $\left(\mathrm{ONOO}^{-}, \mathrm{PN}\right)$ has long been considered a potent nitrating agent implicated in numerous inflammation-mediated diseases. The current work highlights an unexplored oxidation chemistry initiated under conditions of sustained PN exposure. Impetus for this investigation developed from mass spectral results that suggested dimerization of a model peptide with a single tyrosine residue that was first nitrated following extended exposure to PN generated in situ. In attempts to substantiate this dimerization event and divulge the possible mode of linkage between the tyrosine derivatives of the peptide monomers, 3-nitrotyrosine (3-NT) was exposed to sustained fluxes of PN in a two-component PN-generating platform developed in this laboratory. Such exposure afforded products with tandem mass spectrometry and fluorescence spectroscopy profiles indicative of $\mathrm{C}-\mathrm{O}$ coupling between 3-NT moieties. Synthesis and comparative analysis of the $\mathrm{C}-\mathrm{C}$ coupled 3-NT isomer corroborated these findings. Most notably, the mass spectral data of the C-C coupled 3-NT dimer displayed a $226.80 \mathrm{~m} / \mathrm{z}$ peak following exposure to high collision energy, corresponding to symmetric cleavage of the parent dimer peak $(\mathrm{m} / \mathrm{z}=453)$ along with a fragmentation product at $m / z=180.04$ ( $-\mathrm{NO}_{2}$ species). This fragmentation profile was distinct from the $\mathrm{C}-\mathrm{O}$ coupled 3-NT dimer that exhibited a predominant $209.14 \mathrm{~m} / \mathrm{z}$ peak with a small secondary $226.15 \mathrm{~m} / \mathrm{z}$ peak indicative of asymmetric cleavage of the parent dimer. Results of this study indicate that formation of $\mathrm{C}-\mathrm{O}$ coupled 3-NT dimer is promoted by elevated levels of 3-NT formed under high and sustained flux of PN.
\end{abstract}

\section{G Open Access}

Received: 10 November 2018

Accepted: 24 January 2019

Published: 06 March 2019

Copyright (C 2019 by the author(s). Licensee Hapres, London, United Kingdom. This is an open access article distributed under the terms and conditions of Creative Commons Attribution 4.0 International License.
KEYWORDS: peroxynitrite; nitration; dimerization; inflammation; protein aggregation 


\section{ABBREVIATIONS}

PN, Peroxynitrite; RNS, Reactive nitrogen species; NO, Nitric Oxide; XO, Xanthine oxidase; CAT, Catalase; 3-NT, 3-Nitrotyrosine; RP-HPLC, Reversephase high-pressure liquid chromatography; ESI-MS, Electrospray ionization mass spectrometry; MS-MS, Tandem mass spectrometry; di-3-NT $\mathrm{C}_{-\mathrm{C}}, \quad \mathrm{C}-\mathrm{C}$ coupled di-3-nitrotyrosine; di-3-NT $\mathrm{C}_{\mathrm{C}-\mathrm{O}}, \mathrm{C}-\mathrm{O}$ coupled di-3-nitrotyrosine

\section{INTRODUCTION}

Tyrosine nitration has remained tightly associated to the reactive nitrogen species (RNS) peroxynitrite (PN) since the discovery of PN in the early 1990's. Early work exploited the nitration of tyrosine by PN as a strategy to define and support the physiological existence of PN. However, more recently a significant body of work has been aimed at exploring the biochemical and physiological role tyrosine nitration can play in cellular signaling, as a part of host defense, and in the onset of disease [1-4].

The fleeting nature of PN has remained a technical hurdle impeding investigation of PN-mediated nitration, where limitations in PN-production necessitate the use of chemical PN sources [5]. Under these conditions, target tyrosine-containing proteins or peptides are exposed to a burst of PN, affording a snapshot of PN-mediated nitration [6,7]. While this approach has been undoubtedly powerful in identifying proteins and enzymes that exhibit altered function or activity when one or more tyrosine residues have been nitrated, this method ceases to address conditions of chronic inflammation where PN can be continuously generated. As such, one question that has not been posed in the field of PN is, what happens after tyrosine nitration?

We developed a PN-generating platform that mimics the enzymatic production of PN, producing continuous fluxes of precursory species nitric oxide (NO) and superoxide $\left(\mathrm{O}_{2}^{--}\right)$that react in situ to yield PN [8]. The $\mathrm{PN}$-generating platform is a two-component system that is comprised of two silicate disks that have been fabricated individually and contain either photoactivatable metal nitrosyl $\left[\mathrm{Mn}\left(\mathrm{PaPy}_{3}\right)(\mathrm{NO})\right] \mathrm{ClO}_{4}$, the NO source, or xanthine oxidase (XO) and catalase (CAT), the $\mathrm{O}_{2}{ }^{--}$source (Figure 1). When the two disks are placed together, PN formation can be initiated upon addition of hypoxanthine and exposure of the multiwell plate to a low-power visible light source, triggering the simultaneous release of $\mathrm{NO}$ and $\mathrm{O}_{2}{ }^{--}$.

The continuous release of $\mathrm{PN}$ in our platform substantially extends the reaction window of $\mathrm{PN}$-mediated chemistry beyond a single reaction snapshot. Previously, nitrated tyrosine (3-NT, 3-nitrotyrosine) and tyrosine dimer $o, o^{\prime}$-dityrosine (di-tyr) were observed as the only products formed upon exposure of tyrosine to PN [9-11]. The relative formation of 3-NT and di-tyr has been reported to depend largely on the concentration of PN employed in studies, where bolus additions of chemically synthesized PN were employed. Furthermore, only under conditions of low PN and high tyrosine concentrations does di-tyr formation prevail over 3-NT [12]. 


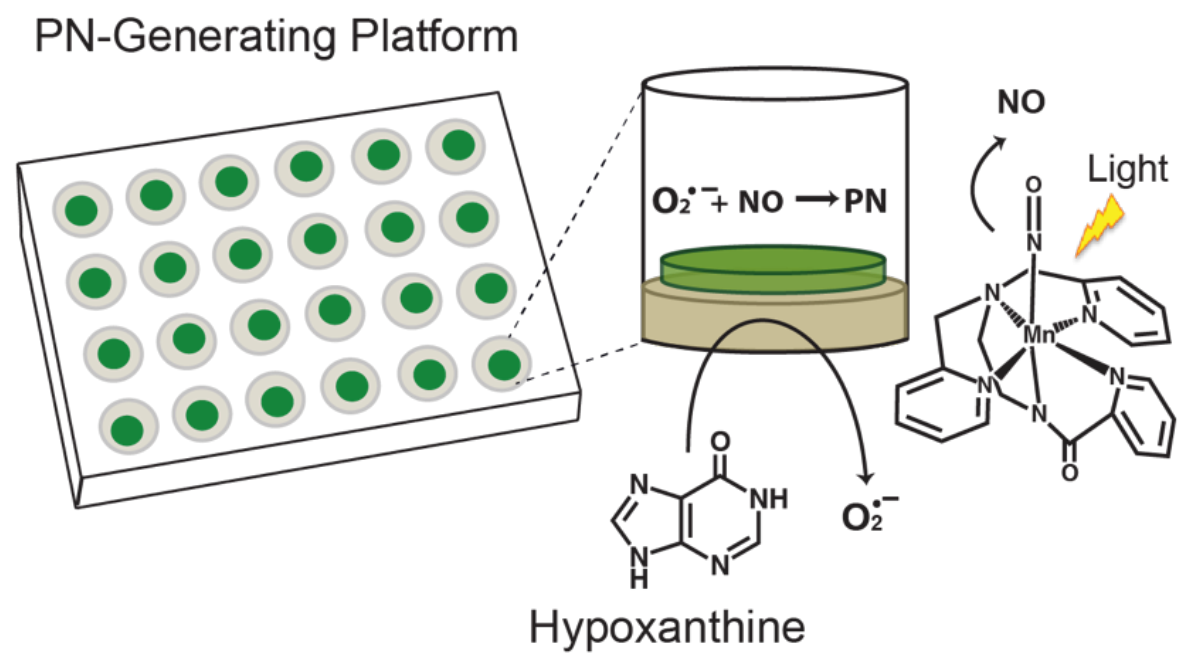

Figure 1. Peroxynitrite-generating platform employed to investigate the chemistry of PN. The individual wells of the platform generate PN in situ in a continuous and sustained fashion. The 24-well plate shown highlights the two-component system, where the $\mathrm{O}_{2}{ }^{-}$-generating component is layered on the bottom of the wells and the NO-generating component is placed on top of this layer. Structure of $\left[\mathrm{Mn}\left(\mathrm{PaPy}_{3}\right)(\mathrm{NO})\right]^{+}$is shown on the right.

Discontinuity in the continuum of tyrosine-specific modification directed by PN spurred our interest in investigating the spectrum of product evolution that can exist upon exposure of tyrosine to sustained and continuous fluxes of PN. As such, we sought to probe the breadth of PN-mediated tyrosine nitration by exploring the post-nitration chemistry of tyrosine. Herein, we report a unique coupling event between nitrated tyrosine amino acid 3-NT following continuous exposure of tyrosine to PN. Dimerization between 3-NT monomers represents an alternative unexplored chemical reaction mediated by $\mathrm{PN}$.

\section{MATERIALS AND METHODS}

\section{Materials}

All chemicals used were analytical or ACS grade unless otherwise noted. Platform components xanthine oxidase, tetramethylorthosilicate, and hypoxanthine were purchased from Sigma-Aldrich (St. Louis, MO, USA). Catalase was procured from Spectrum Chemicals MFG Corp (New Brunswick, NJ, USA). HPLC grade solvents acetonitrile (MeCN), dimethylformamide (DMF) and trifluoroacetic acid (TFA), and 3-nitrotyrosine (3-NT) were obtained from Sigma-Aldrich (St. Louis, MO, USA).

\section{Synthesis of the Two-Component Peroxynitrite-Generating Platform}

Peroxynitrite-generating platforms were constructed as described in our previous publication [8,13]. In short, individual $\mathrm{NO}$ and $\mathrm{O}_{2}{ }^{--}$ generating sol-gel pieces were synthesized through the encapsulation of $\left[\mathrm{Mn}\left(\mathrm{PaPy}_{3}\right)(\mathrm{NO})\right]_{\mathrm{ClO}_{4}}\left(\mathrm{PaPy}_{3}=N, N\right.$-bis(2-pyridylmethylamine)- $N$-ethyl-2pyridine-2-carboxamide) or $\mathrm{XO}$ and $\mathrm{CAT}$ solutions into respective tetramethylorthosilicate matrices. $0.600 \mathrm{~mL}$ aliquots of the metal nitrosyl 
sol-gel solution and $0.800 \mathrm{~mL}$ aliquots of the XO-CAT sol-gel were then transferred into their corresponding plates and allowed to solidify and dry in the dark for 1 week at $4{ }^{\circ} \mathrm{C}$. Activity of the final sol-gel pieces were analyzed at random prior to use $[8,13]$. The individual sol-gel pieces were then combined into single wells of a 24-well plate to afford the final PN-generating system that affords $\sim 4 \mu \mathrm{M} \mathrm{min}^{-1}$ fluxes of PN. Generation of $\mathrm{NO}, \mathrm{O}_{2}{ }^{--}$, and $\mathrm{PN}$ was initiated with exposure of the plate to low power $\left(10 \mathrm{~mW} / \mathrm{cm}^{2}\right)$ broadband light and the addition of hypoxanthine (final concentration $250 \mathrm{mM}$ unless otherwise noted).

\section{Peptide Syntheses and Purification}

The YTV peptide (KKYTVSINGKKITVSI) was synthesized using Fmoc synthesis on a Liberty 1 Peptide Synthesizer with Discover ${ }^{\circledR}$ microwave platform (CEM, Matthews, NC, USA) on a $0.1 \mathrm{mmol}$ scale, and monitored with PepDriver software [14]. Peptides were assembled on a Rink-amide ChemMatrix ${ }^{\circledR}$ resin (Sigma-Aldrich, St. Louis, MO, USA). All amino acids were purchased from Aapptec (Louisville, KY, USA). The deprotection of the Fmoc group was achieved using a $0.1 \mathrm{M}$ solution of hydroxybenzotriazole (HOBT) and 20\% piperidine in DMF. $0.625 \mathrm{M}$ diisopropylcarbodiimide (DIC) and 1.25 M HOBT in DMF were used in the coupling reactions, and all couplings were performed at 4 equivalents of Fmoc-amino acid. Each amino acid was double coupled.

A cleavage cocktail consisting of $10 \mathrm{~mL}$ of TFA, $0.5 \mathrm{~mL}$ each of 1,2ethanedithiol (EDT) and liquefied phenol, and $1 \mathrm{~mL}$ of triisopropylsilane (TIPS), was added to each vessel of dried resin and reacted for $2 \mathrm{~h}$ followed by filtration. The filtrate was added to $90 \mathrm{~mL}$ of cold, dry diethyl ether for precipitation. The precipitate was collected by centrifugation, and the ether was discarded. The pellet was dissolved in $20 \mathrm{~mL}$ of $1: 1 \mathrm{H}_{2} \mathrm{O} / \mathrm{MeCN}$ (1\% formic acid) and lyophilized.

Peptides were purified by RP-HPLC on Vydac (Hesperia, CA, USA) semi-preparative C18 columns. Fractions were collected and analyzed by ESI-MS on a Micromass (Wythenshawe, UK) ZMD mass spectrometer to confirm the correct molecular weight.

\section{HPLC Analysis of Dimeric Products di-3NT $\mathrm{C}_{\mathrm{O}-\mathrm{o}}$}

Analysis of well content was carried out using a Hewett Packard 1050 Series HPLC (Palo Alto, CA, USA), equipped with a $4.6 \mathrm{~mm} \times 250 \mathrm{~mm} \mathrm{C18}$ $5 \mathrm{U}$ reverse-phase Econosphere Alltech column (Deerfield, IL, USA) and diode array detector. Samples were manually injected into a Rheodyne 7225 injection loop and eluted over $30 \mathrm{~min}$ with $\mathrm{H}_{2} \mathrm{O} / \mathrm{MeCN}$ (both containing $0.1 \% \mathrm{TFA}$ ) at a flow rate of $0.8 \mathrm{~mL} / \mathrm{min}$. The established solvent method was as follows: 0-15 min isocratic 98:2, 15.01-20 gradient 70:30, 20.01-25 gradient 98:2, and 25.01-30 isocratic 98:2. Detection wavelengths included $220 \mathrm{~nm}, 280 \mathrm{~nm}, 310 \mathrm{~nm}$ and $350 \mathrm{~nm}$ with bandwidths of $4 \mathrm{~nm}$. Chromatographic peaks were collected and lyophilized (VirTis bench top 
SLC lyophilizer, Gardiner, NY, USA) for fluorescence and mass spectral analysis.

\section{Fluorescence Analysis}

Lyophilized samples were dissolved in $2 \mathrm{~mL}$ of 50:50 $\mathrm{H}_{2} \mathrm{O}$ :MeCN $(0.1 \%$ formic acid) solution and analyzed by fluorescence spectroscopy (Varian Cary Eclipse, Mulgrave, Australia) with slit widths set to $10 \mathrm{~nm}$. An initial excitation and emission scan was completed to define max emission and excitation bands.

\section{Synthesis of 3-Bromo-5-Nitrotyrosine (3-Br-5-NT)}

A $50 \mathrm{~mL}$ round bottom flask was charged with $100 \mathrm{mg}$ of 3-bromotyrosine (385 mmol) and $2 \mathrm{~mL}$ of neat nitric acid was added to the solid dropwise. The white solid quickly dissolved in the rapidly stirred acid and afforded a deep orange-yellow solution. To this solution, $2 \mathrm{~mL}$ of diethyl ether was added when a fluffy pale yellow solid separated. The solid was collected and thoroughly washed with diethyl ether. The crude solid was then recrystallized from methanol to obtain a yellow microcrystalline solid. Yield: 82\%. ${ }^{1} \mathrm{H}$ NMR (500 MHz, Varian Unity): 8.07 (s), 7.91 (s), 4.32 (t), 3.18 (m). IR: $3146.55 \mathrm{~cm}^{-1}(\mathrm{w}), 1735.57$ (s), $1544 \mathrm{~cm}^{-1}$ (s). ESI-MS (M + H) $: 307$ and $306 \mathrm{~m} / \mathrm{z}$.

\section{Synthesis of C-C Coupled 3-NT Dimer di-3-NT $\mathrm{C}_{\mathrm{C}}$}

Synthesis of the C-C coupled 3-NT dimer was achieved in reaction of the brominated nitrotyrosine derivative 3-Br-5-NT (50 mg, $163 \mathrm{mmol}$ ) and 3-NT (55 mg, $243 \mathrm{mmol}$ ) in the presence of [Cu( $\left.\mathrm{MeCN})_{4}\right]_{\mathrm{BF}}(75 \mathrm{mg}, 238 \mathrm{mmol})$ and $\mathrm{Cs}_{2} \mathrm{CO}_{3}$ (165 mg, $506 \mathrm{mmol}$ ) under anaerobic conditions in $20 \mathrm{~mL}$ of dry DMF. The reaction mixture was allowed stir for $1 \mathrm{~h}$ and then the solvent was evaporated down to one-third the original volume. Addition of $6-8 \mathrm{~mL}$ of a 50:50 methanol/ethyl acetate solution resulted in a fine powdery solid. The solid was filtered off and the filtrate was collected. Addition of dry diethyl ether to this filtrate afforded a pale yellow product. Yield: 12\%. ${ }^{1} \mathrm{H}$ NMR (500 MHz, Varian Unity): 8.05 (s), 8.02 (s), 7.90 (s) 7.54 (d) 7.17 (d) $4.12(\mathrm{t}), 3.19(\mathrm{~m})$. ESI-MS $(\mathrm{m} / \mathrm{z})=451[\mathrm{M}+\mathrm{H}]^{+}$.

\section{RESULTS}

\section{Sustained Exposure of Model Peptide YTV to PN Yield a Post- Nitration Dimeric Product}

In our initial efforts to capture the spectrum of chemistry observed under sustained exposure of tyrosine to $\mathrm{PN}$ we employed a model peptide YTV. In these studies, the PN-generating system was prepared to facilitate maximal PN chemistry, incorporating $25 \mathrm{mM} \mathrm{NaHCO} 3$ (4 mM final concentration) to a pH 7.4 in $0.01 \mathrm{M}$ phosphate buffer solution. Under these conditions formation of reactive $\mathrm{PN}$ analogue nitrosoperoxocarbonate anion $\left(\mathrm{ONOOCO}_{2}{ }^{-}\right)$is promoted, which gives rise to strong oxidants $\mathrm{CO}_{3}{ }^{-}$ 
and $\mathrm{NO}_{2}$. The chemical transformations of YTV were analyzed after $20 \mathrm{~min}$

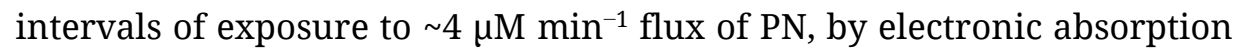
spectroscopy. Over the course of the first two time-intervals (40 total min of PN exposure) the $370 \mathrm{~nm}$ absorption band, corresponding to 3-NT formation, increased as expected. However after the third interval of exposure (60 total min of PN exposure), dramatic spectral changes were observed with a sharp diminution in intensity and slight shift in the $\lambda_{\max }$, as highlighted in Figure 2. To explore the changes in the absorbance spectrum the well content was processed by high-pressure liquid chromatography (HPLC). Peaks from the separation were collected and further analyzed by mass spectrometry (MS). The analytical results indicate dimerization between two nitrated monomeric YTV units.

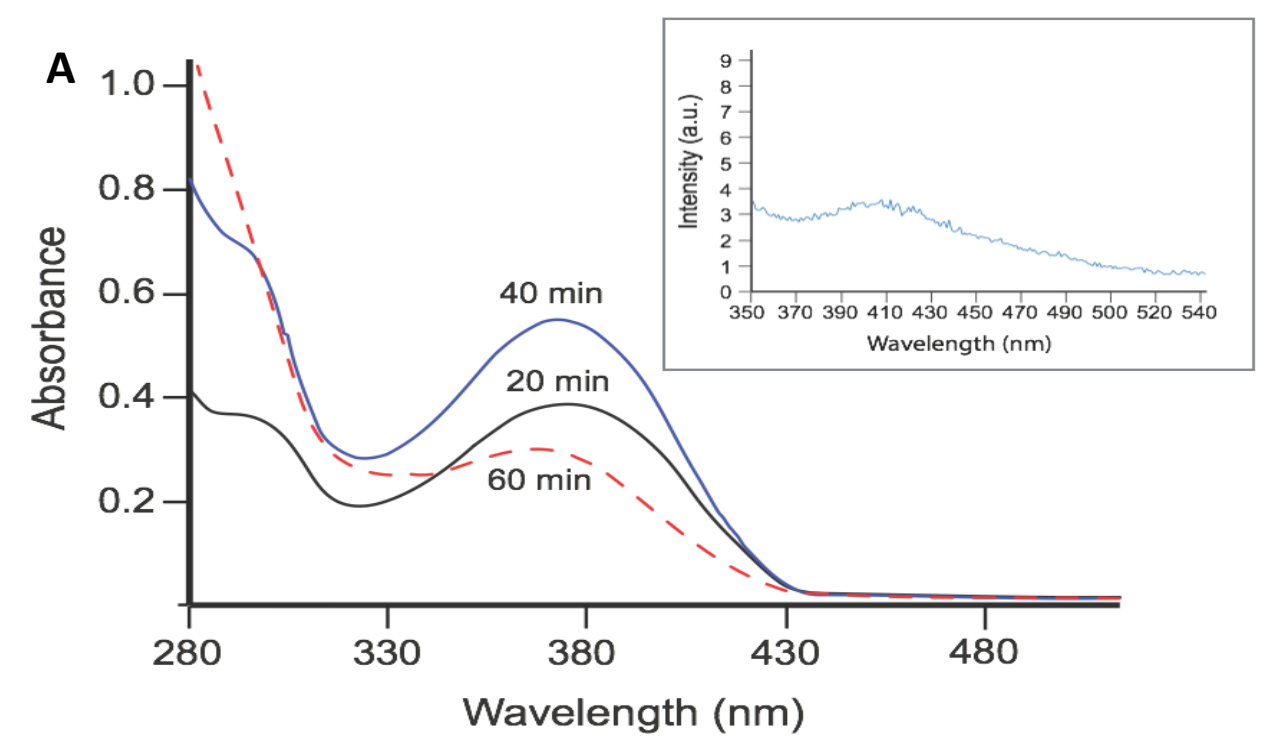

B

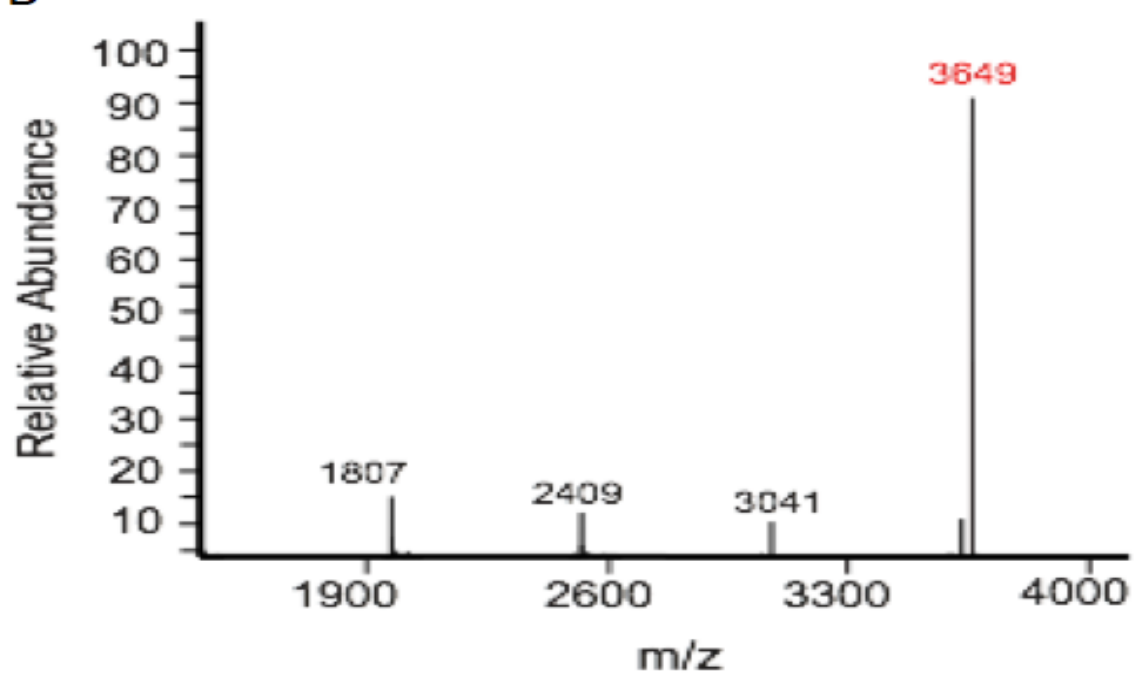

Figure 2. PN directs dimerization between post-nitrated YTV peptides. (A) Electronic absorbance spectra of the well content YTV peptide exposed to PN within the wells of the platform for 20 min (solid black line), $40 \mathrm{~min}$ (solid blue line), and $60 \mathrm{~min}$ (dotted red line). (Inset) Emission spectrum of the dimeric nitrated-YTV product, excited at $310 \mathrm{~nm}$; (B) Deconvoluted mass spectrum of the collected YTV product, with the $[\mathrm{M}+\mathrm{H}]^{+}$ peak indicative of dimerization between two nitrated YTV units highlighted in red. 
Dimerization was first presumed to occur with the observed $[\mathrm{M}+\mathrm{H}]^{+}$ peak at 3649, corresponding to linkage between two monomer YTV units post-nitration (Figure 2B). Secondary analysis of this dimeric product by fluorescence spectroscopy featured a biphenyl-type emission profile, supporting coupling between aromatic residues (Figure 3A, inset) [15-17]. Given the primary sequence of the model peptide, the tyrosine residue appears to be the likely site of dimerization.
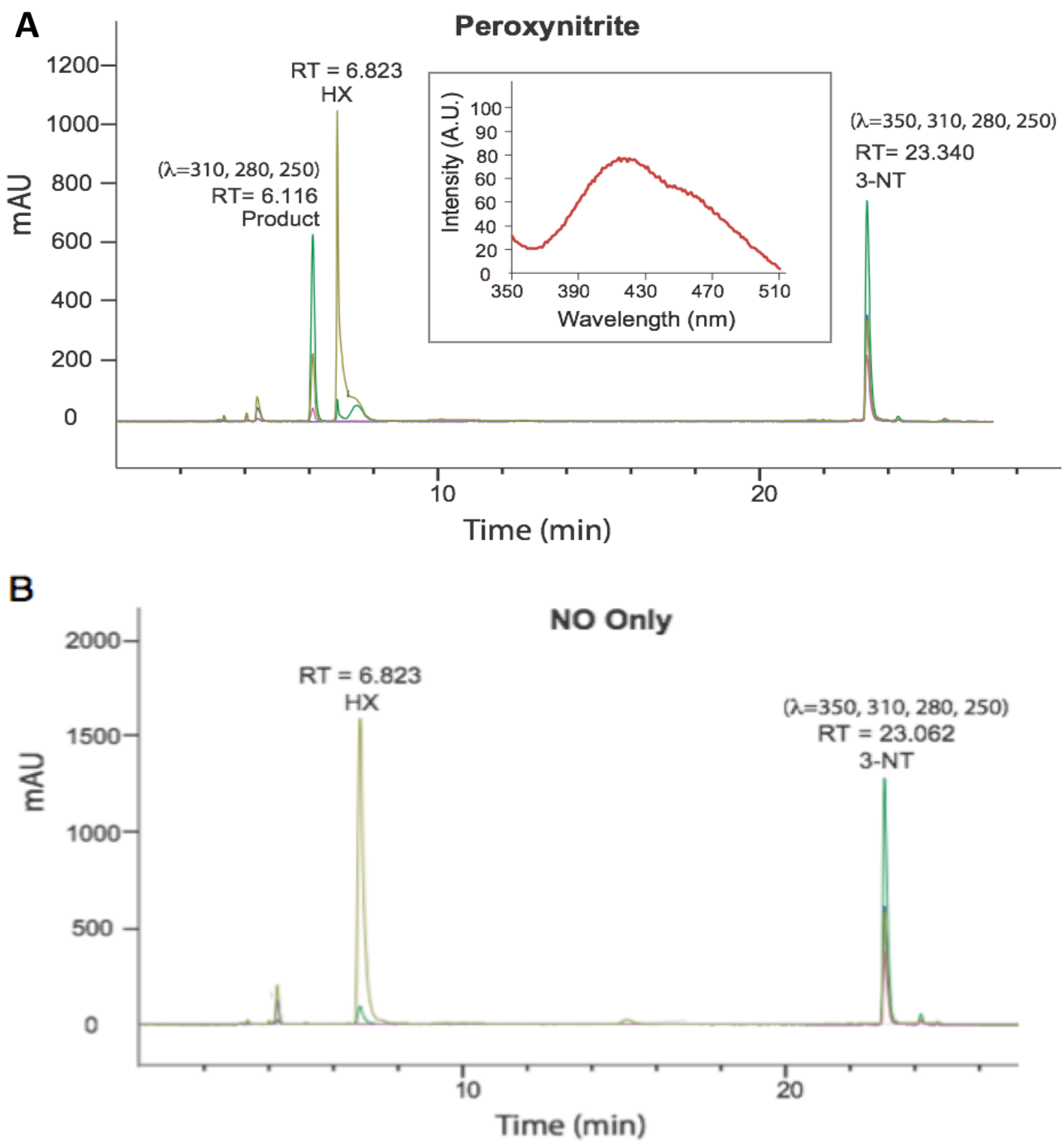

Figure 3. (A) HPLC chromatogram collected of the analyte collected from the PN-generating well content following exposure of 3-NT to PN for $30 \mathrm{~min}$ (Inset: fluorescence emission spectrum of the RT = 6.116 product) and (B) the corresponding control study completed in the presence NO only.

Taken together, these findings suggest that tyrosine residue within the YTV peptide is nitrated within the first $40 \mathrm{~min}$ of exposure to PN within the wells of the platform. We hypothesize that as the concentration of nitrated YTV peptide (YTV-NO $\mathrm{N}_{2}$ ) builds in the system, the nitrated tyrosine residues become vulnerable to oxidation under sustained exposure to $\mathrm{PN}$ and gives rise to dimerization between $\mathrm{YTV}-\mathrm{NO}_{2}$ monomer units. 
Therefore, to investigate the feasibility that PN mediates coupling between nitrated tyrosine residues, we proceeded to study the chemistry between PN and 3-NT.

\section{PN Mediated Dimerization of 3-NT Monomers}

To elucidate the dimerization processes between 3-NT residues of YTV peptide monomers, we independently investigated the chemistry of 3-NT with PN. In these studies, we incubated $\sim 160 \mu \mathrm{M}$ of 3-NT within the PN-generating platform under the same well conditions defined in the previous YTV study, however limiting the exposure to a single $30 \mathrm{~min}$ interval. After $30 \mathrm{~min}$ of exposure the well content was analyzed by absorption spectroscopy. A hypsochromic shift in the $\lambda_{\max }$ from 370 to $350 \mathrm{~nm}$, in concordance with the profile changes observed between the spectra of the well content of YTV experiment after treatment of $60 \mathrm{~min}$ of PN exposure, was observed. These changes in the absorption spectrum were also qualitatively observable, with the initial vibrant yellow color of the 3-NT solution gradually diminishing to a pale yellow hue.

The well contents were then purified and analyzed by HPLC, equipped with a multi-channel diode array detector, revealing formation of a single predominant species (Figure 3A), featuring an absorbance profile distinct from 3-NT. The product peak was detectable at 280, 250, and $310 \mathrm{~nm}$ but silent to $350 \mathrm{~nm}$, while 3-NT shows signals over all four wavelengths. Further, the suspected product was absent when 3-NT was exposed to NO only (Figure 3B).

Tandem mass spectral analysis (MS-MS) of the HPLC-purified product using a LTQ-Orbitrap mass spectrometer (electron spray ionization, positive ion mode, CID) revealed $\mathrm{m} / \mathrm{z}$ peaks at $451.40[\mathrm{M}+\mathrm{H}]$ and 226.12 $[\mathrm{M}+2 \mathrm{H}]$ confirming the formation of the 3-NT dimer (di-3NT). Fragmentation of the dimer peak $(451.40([\mathrm{M}+\mathrm{H}]))$ required three times standard collision energy ( $60 \mathrm{eV}$ ) and decomposed to yield predominant peaks at $m / z$ 435.32, 417.28, 389.91, 336.23, 226.15 and 209.14 (Figure 4). Peaks $m / z$ 435.32, 417.28, 389.91, 336.23 correspond to consecutive $-\mathrm{H}_{2} \mathrm{O}$ and $-\mathrm{HCO}_{2}$ losses from the parent dimer and a potential rearrangement product $(\mathrm{m} / \mathrm{z}=336.23)$, reported previously in the fragmentation profile of 3,0'-dityrosine [18].

The predominant peaks at $226.15 \mathrm{~m} / \mathrm{z}$ and $209.14 \mathrm{~m} / \mathrm{z}$ suggest an asymmetric coupling event between the 3-NT monomer units, corresponding to two fragments that differ by a mass of $17 \mathrm{Da}$. Additionally, fluorescence analysis of the corresponding product featured an emission band at $420 \mathrm{~nm}$ with a $456 \mathrm{~nm}$ shoulder peak upon excitation at $268 \mathrm{~nm}$ (Figure 3A, inset). The profile of the emission band supports an asymmetric coupling between 3-NT units, in contrast to the reported symmetric peak profile of o,o'-dityrosine centered at $410 \mathrm{~nm}$. Taken together, the results suggest 3-NT monomers asymmetrically combine upon exposure to $\mathrm{PN}$ to afford a $\mathrm{C}-\mathrm{O}$ coupled 3-NT dimer product (di-3NT $\mathrm{C}-0$ ), a coupling modality reported previously between tyrosine monomers [19]. 

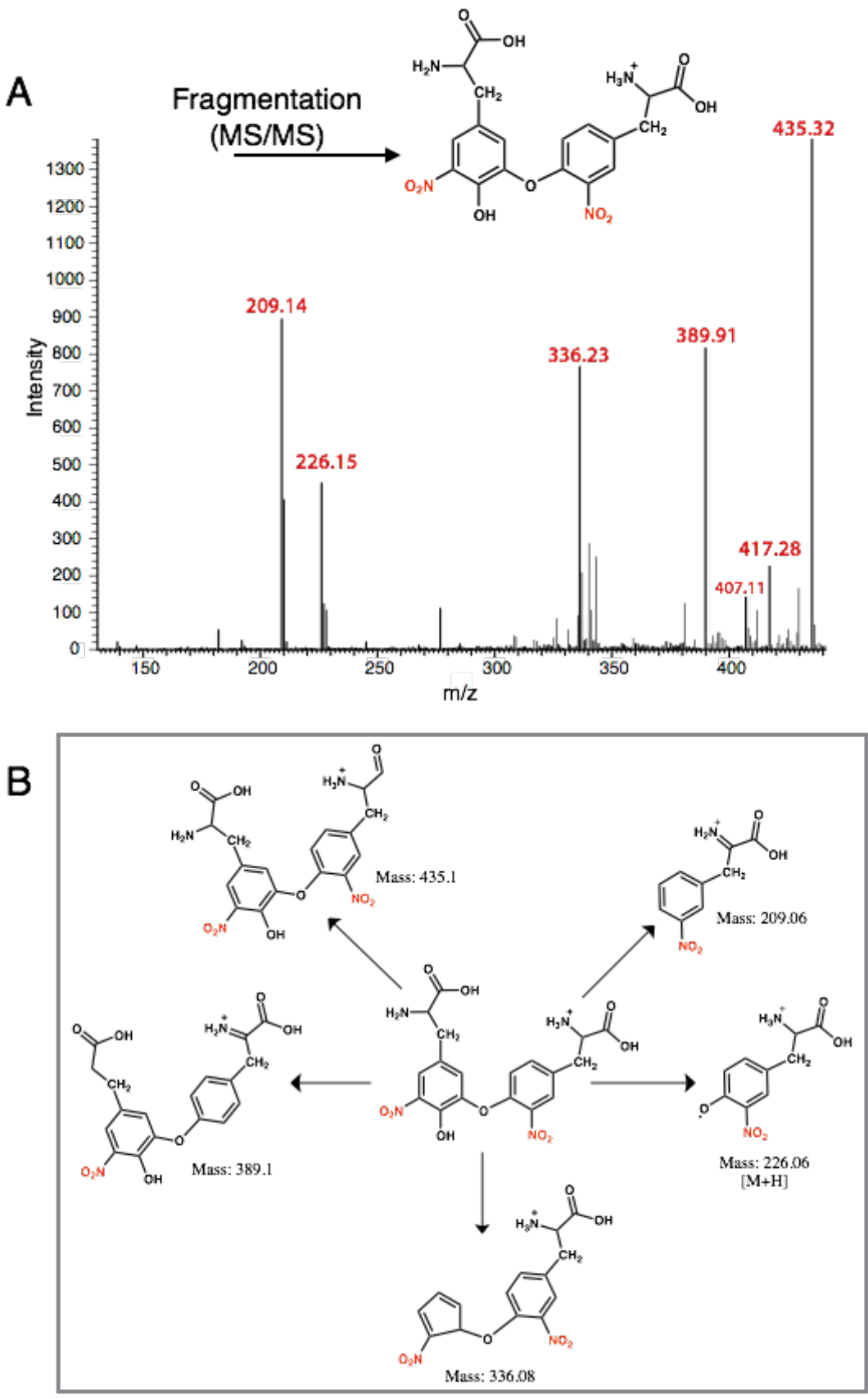

Figure 4. MS-MS analysis of the 3-NT coupled product (di-3NT $\mathrm{C}_{\mathrm{C}-\mathrm{O}}$ ): (A) The MS of di-3NT $\mathrm{C}_{\mathrm{C}-\mathrm{O}}$; (B) Possible fragmentation products derived from di-3NT $\mathrm{N}_{\mathrm{C}-\mathrm{O}}$.

\section{NT Monomers Couple via a C-O Linkage}

Based on structural features inferred from the mass spectral fragmentation pattern and fluorescence emission profile we attempted to synthesize the analogous $\mathrm{C}-\mathrm{C}$ coupled isomer of di-3NT (di-3NT $-\mathrm{C}$ ) to confirm the fragmentation pattern obtained in the $\mathrm{C}-\mathrm{O}$ coupled product. Successful synthesis of di-3NT $\mathrm{C}_{\mathrm{C}-\mathrm{c}}$ was achieved in an Ullman type reaction that employs a cuprous catalyst and an inorganic base to couple an activated aryl halide with a nucleophile [20]. Aryl halides are strongly activated by electron withdrawing groups that enhance electrophilicity by 
pulling electron density from the $\pi$-system, and the $\mathrm{NO}_{2}$ group represents the most strongly activating substituent [21].

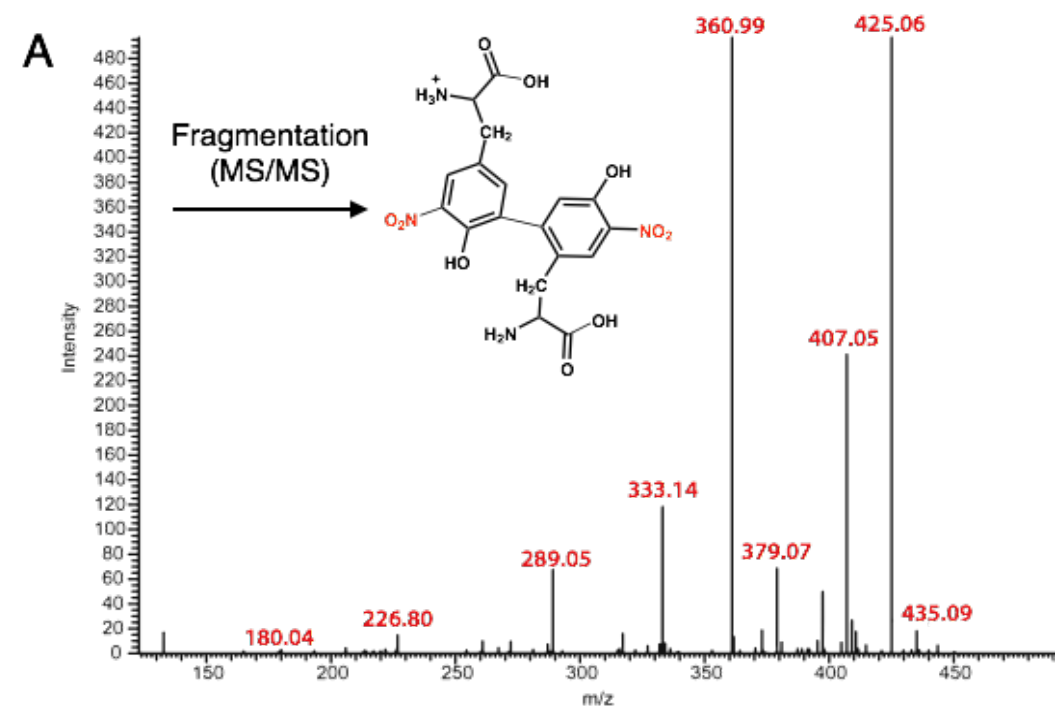

B

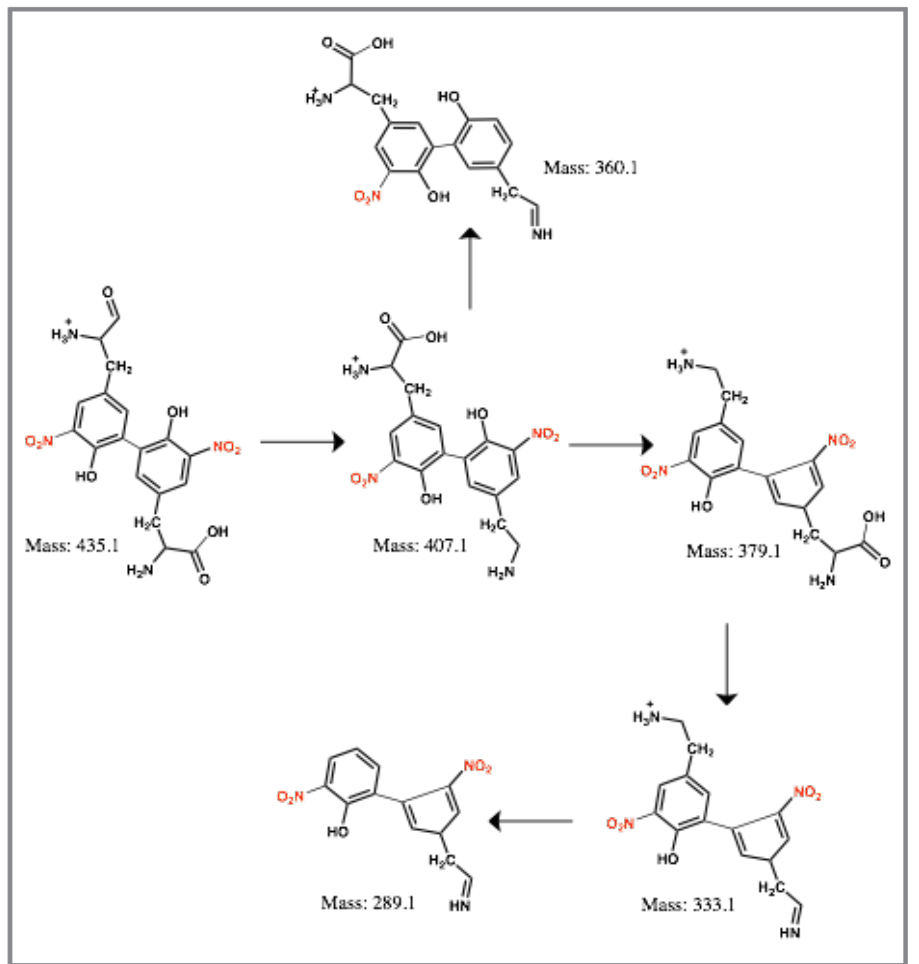

Figure 5. MS-MS analysis of the 3-NT coupled product (di-3NT $\mathrm{C}_{\mathrm{C}}$ ): (A) The MS of di-3NT $\mathrm{C}_{-\mathrm{C}}$; (B) Possible fragmentation products derived from di-3NT $-\mathrm{C}$.

The nucleophilic aromatic substitution reaction yielded di-3NT $\mathrm{N}_{\mathrm{C}-\mathrm{c}}$ upon reaction of 3-NT (nucleophile) with aryl halide 3-bromo-5-nitrotyrosine in the presence of a cuprous catalyst (Tetrakis(acetonitrile)copper(I) tetrafluoroborate, $\left[\mathrm{Cu}(\mathrm{MeCN})_{4}\right] \mathrm{BF}_{4}$ ) and an inorganic base $\mathrm{Cs}_{2} \mathrm{CO}_{3}$ in dimethyl formamide (DMF). The resulting pale yellow powder was collected and analyzed by mass spectrometry, displaying a parent dimer peak at $m / z$ 451.20. Fragmentation of this peak under equivalent collision conditions yielded a fragmentation pattern (Figure 5) distinct from that of 
di-3NT (Figure 3B), with predominant $m / z$ values at 435.09 , 407.05, 379.07, $360.99,333.14,289.05,226.80$ and 180.40. Fragmentation peaks $m / z$ 435.09, $407.05,379.07,333.14$, and 289.05, correspond to sequential losses of $-\mathrm{OH}$, $-\mathrm{HCOOH},-\mathrm{CO}$ groups fragment groups and corresponding rearrangement events that are featured in Figure 4B, and the fragmentation peaks at $226.80 \mathrm{~m} / \mathrm{z}$ and $180.4 \mathrm{~m} / \mathrm{z}$ correspond to a 3-NT monomer unit and the loss of a nitro (46 Da) group from this monomer unit, respectively. The loss of the nitro group from the 3-NT unit represents a characteristic feature observed even with standard 3-NT, where a predominant $181 \mathrm{~m} / \mathrm{z}$ peak is commonly observed in a standard sample. Finally, the strong peak at $425.06 \mathrm{~m} / \mathrm{z}$ corresponds to loss of $\mathrm{C}_{2} \mathrm{H}_{2}$ from the parent dimer peak at $\mathrm{m} / \mathrm{z}$ 451.20 [18].

The fluorescence profile of di-3NT $\mathrm{C}_{\mathrm{C}-\mathrm{C}}$ (Figure 6) features a significantly more symmetric emission band at $470 \mathrm{~nm}$ compared to that of the asymmetric di-3NT $\mathrm{N}_{\mathrm{C}-\mathrm{o}}$ species (Figure $3 \mathrm{~A}$ ). Taken together, these spectral evidences clearly establish two different modes of coupling of two 3-NTs (di-3NT $\mathrm{N}_{\mathrm{C}} \mathrm{c}$ and di-3NT $\mathrm{N}_{-0}$ ). Comparison of the 451.2(4) fragmentation patterns of the isomers highlights a dramatic variation in the observed peak profile (Figures 4 and 5). In addition, peaks corresponding to the separation of the dimer unit into monomeric units are also distinct. Fragmentation of the proposed $\mathrm{C}-\mathrm{O}$ coupled 3-NT dimer yields fragmentation products identified at $226.15 \mathrm{~m} / \mathrm{z}$ and $209.14 \mathrm{~m} / \mathrm{z}$ while the synthetically derived $\mathrm{C}-\mathrm{C}$ coupled 3-NT dimer affords fragmentation products identified at $226.80 \mathrm{~m} / \mathrm{z}$ and $180.4 \mathrm{~m} / \mathrm{z}$.

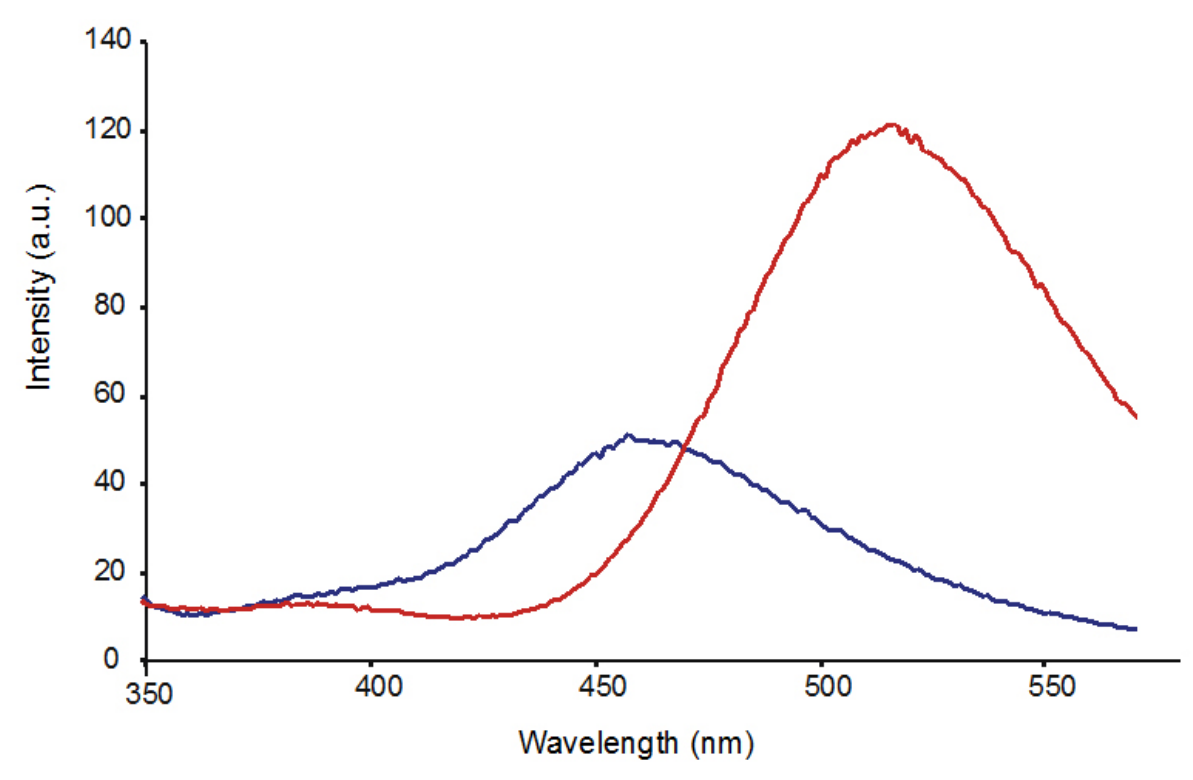

Figure 6. Fluorescence emission spectrum of di-3NT $\mathrm{N}_{\mathrm{c}-\mathrm{c}}$ at $\mathrm{pH} 7.4$ (blue line) and 10.0 (red line) upon excitation at $310 \mathrm{~nm}$.

\section{DISCUSSION}

The preceding results highlight a previously unexplored PN-mediated oxidation pathway that is initiated upon nitration of tyrosine. Post- 
translational nitration of tyrosine has long been the center of PN-mediated chemistry because it yields the quantifiable product 3-NT that provides a tangible marker of PN. However, the possibility that this tyrosine derivative could be further modified to form alternative products has not been explored.

At local sites of inflammation reactive species such as $\mathrm{PN}$ are generated for extended periods. Unfortunately, replicating such conditions chemically has proven difficult until recently. Using a two-component PN-generating platform that mimics sustained release of the reactive nitrogen species $\left(\sim 4 \mu \mathrm{M} \mathrm{min}{ }^{-1}\right)$ we were able to probe and monitor the evolution of PN-mediated chemistry. Initial investigation into the continuum of PN-mediated nitration was performed using a model 16-mer $\beta$-hairpin peptide YTV which contained a single tyrosine residue within the primary sequence. Continuous exposure of YTV to PN within the PN-generating platform revealed a dynamic profile of product formation, where the tyrosine nitration predominated in the first $40 \mathrm{~min}$ of exposure. However, as the concentration of nitrated-YTV $\left(\mathrm{YTV}-\mathrm{NO}_{2}\right)$ built, this species was suspected to undergo secondary oxidation that resulted in the dimerization of YTV-NO $\mathrm{N}_{2}$ monomers.

In efforts to probe the post-nitration dimerization event between YTV-NO $\mathrm{N}_{2}$ units, we directly investigated the chemistry between 3-NT and PN. Exposure of 3-NT to PN afforded a single predominant product that was isolated by HPLC and analyzed by absorption spectroscopy and MS-MS to be a dimeric species. Secondary mass spectral fragmentation of the 3-NT dimer suggested asymmetric coupling between 3-NT monomers, following exposure of 3-NT to PN. Comparison of the MS-MS fragmentation profile of this 3-NT dimer (di-3NT $\mathrm{N}-\mathrm{O}$ ) to synthetic $\mathrm{C}-\mathrm{C}$ coupled di-3NT $\mathrm{N}_{\mathrm{C}} \mathrm{C}$ dimer corroborated the $\mathrm{C}-\mathrm{O}$ linkage modality, demonstrating distinct fragmentation fingerprints.

Compilation of these findings supports PN-mediated oxidation of 3-NT monomers to yield di-3-NT $\mathrm{N}_{\mathrm{C}-\mathrm{o}}$. Coupling between the nitrated tyrosine units most likely proceeds through the oxidation of the phenol moiety by strong oxidants $\mathrm{CO}_{3}{ }^{-{ }^{-}}$and $\mathrm{NO}_{2}\left(\mathrm{CO}_{3}{ }^{-{ }^{-}}, \mathrm{E}^{\circ}=1.759 \mathrm{~V}\right.$ and $\left(\mathrm{NO}_{2}, \mathrm{E}^{\circ}=1.04 \mathrm{~V}\right)$. Formation of the resulting phenoxy radical and radical dimerization events are both favored with highly substituted phenols, most commonly when a substituent is present ortho to the hydroxyl group. Radical coupling reactions as shown in Figure 7A then lead to the formation of the $\mathrm{C}-\mathrm{O}$ coupled product di-3-NT $\mathrm{C}-\mathrm{O}$.

Taken together, results from the study highlight the dynamic chemical spectrum of tyrosine modification mediated by PN (Figure 7B). The continuum of $\mathrm{PN}$-mediated tyrosine modification is initiated as $\mathrm{PN}$ directs nitration through the formation of reactive intermediate $\mathrm{ONOOCO}_{2}^{-}$that forms as $\mathrm{PN}$ reacts with $\mathrm{CO}_{2}$ in the system. The highly reactive $\mathrm{ONOOCO}_{2}^{-}$ directs facile nitration of tyrosine via secondary radical species $\mathrm{CO}_{3}{ }^{-}$ and $\mathrm{NO}_{2}$ that oxidize and nitrate the phenol moiety of tyrosine ortho to the hydroxide. Over time, the product distributions shift towards equal 
parts tyrosine and 3-NT, and the chemistry of the system transforms in response to the dramatic difference in chemical properties of tyrosine and 3-NT. The $\mathrm{pK}_{\mathrm{a}}$ of 3-NT is 3-orders of magnitude lower than tyrosine, making it increasingly susceptible to proton-coupled electron transfer chemistry relative to tyrosine. It is important to note here that redox measurement on tyrosine and 3-NT indicate that the latter is more difficult to oxidize (Figure 8). As a consequence, oxidation of 3-NT occurs only when the 3-NT concentration reaches a critical level and the PN-flux remains relatively high as is the case in the wells of our PN-generating platform (Figure 7). In previous work, di-3NT $\mathrm{N}_{\mathrm{C}}$ has been identified as the major product at low steady-state concentrations of PN [12].

A
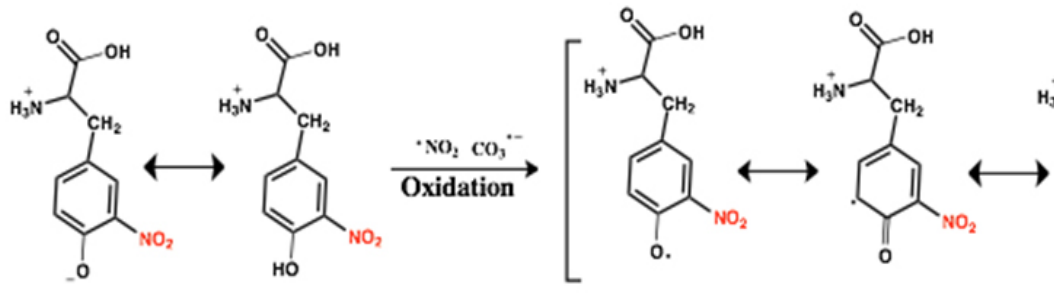

Phenoxy Radical Formation

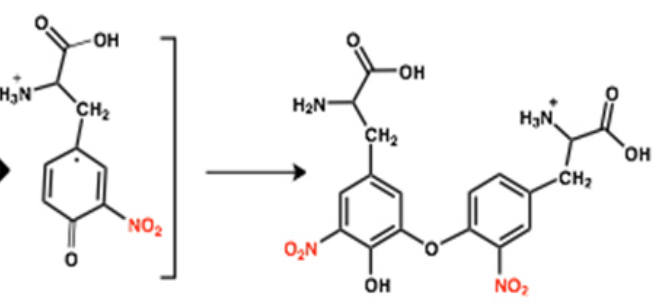

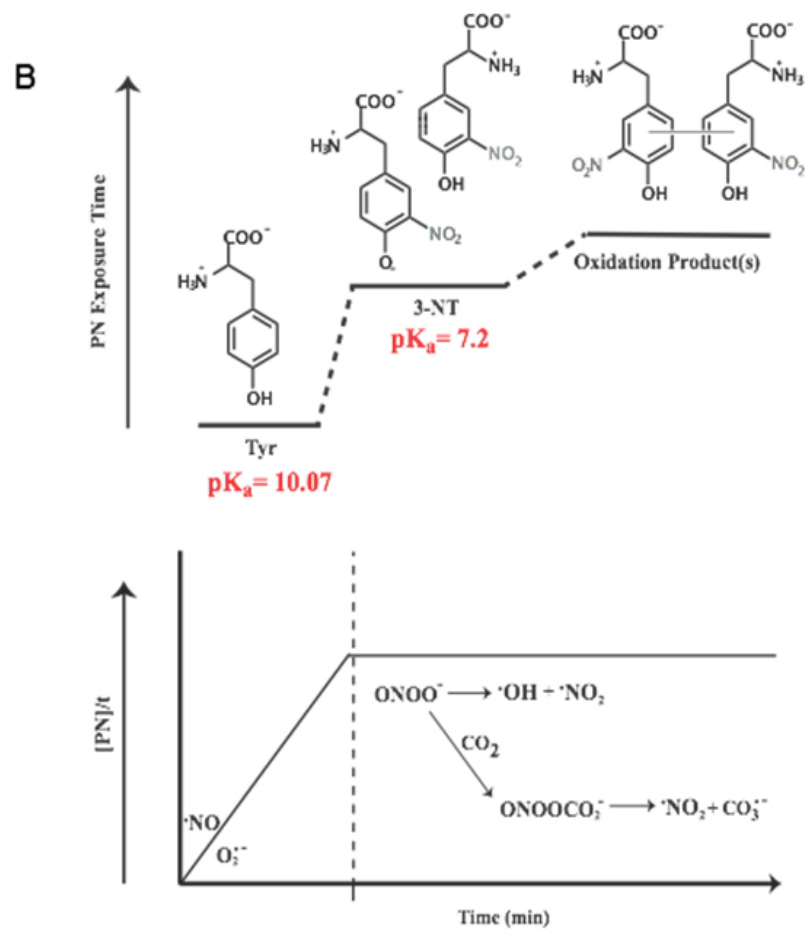

Figure 7. Proposed chemical profile of PN-mediated nitration tyrosine under sustained and continuous exposure to PN, where tyrosine begins as the predominant species. As the concentration of 3-NT builds, which features chemical properties unique from tyrosine, secondary dimerization species become accessible. (A) Radical coupling reactions lead to the formation of the $\mathrm{C}-\mathrm{O}$ coupled product di-3-NT $\mathrm{C}_{\mathrm{O}}$; (B) Dynamic chemical spectrum of tyrosine modification mediated by PN. 
SWEEP: Tyrosine and 3-Nitrotyrosine (GC Electrode)

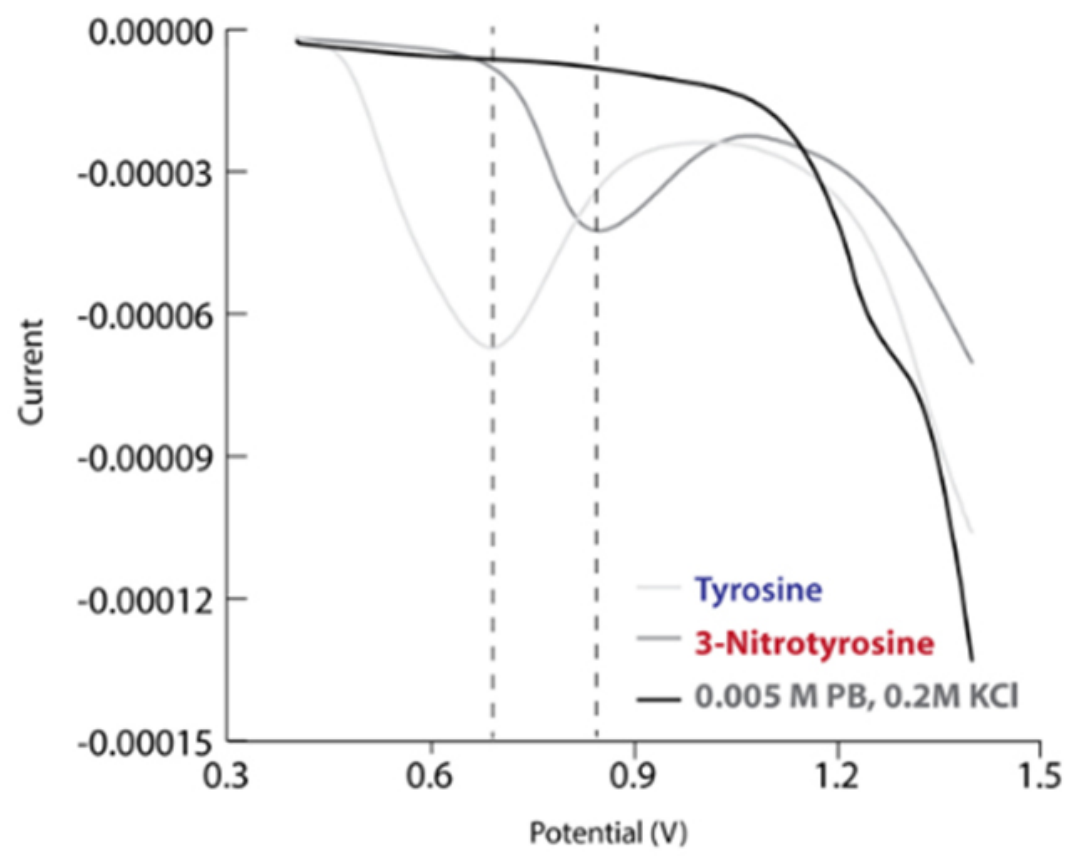

Figure 8. Differential pulse polarograms of tyrosine and 3-NT in phosphate buffer.

\section{CONCLUSION}

Results of the present study reveal an alternative pathway of peptide crosslinking through $\mathrm{C}-\mathrm{O}$ coupling between nitrated tyrosine residues upon prolonged exposure to high PN flux. This pathway could explain the formation of stable protein aggregates observed in tissues under chronic inflammatory conditions where tyrosine residues have been found to play a critical role [22,23]. Although nitration of tyrosine in protein has been considered as the predominant consequence of PN exposure, it is now apparent that 3-NT could in fact be an intermediate in the formation of an array of unsuspected and unexplored PN-mediated products. Systems capable of evolving PN for extended periods of time such as our two-component PN-generating platform are therefore essential to uncover the chemistry of this reactive nitrogen species with biomolecules.

\section{SIGNIFICANCE}

Critical link between PN-mediated nitration of tyrosine and diseased states has now been demonstrated by the identification of this modification at critical tyrosine residues within protein and enzymes collected from in vitro and in vivo sources [1,4,7]. Although identification of the post-translational modification in collected tissue samples and cellular assays has silenced skepticism regarding the physiological relevance of this PN-mediated process, biochemical and proteomic exploration of PN pathophysiology remains at its nascent stage due to technical difficulties encountered in sustained generation of PN in laboratory settings [6]. Previous synthetic methods employed harsh 
chemical conditions that required rapid basification of the resulting solutions as an approach to stabilize the fleeting nature of this reactive nitrogen species. Unfortunately, this approach suffers from rapid decomposition of PN upon addition to buffered samples [5,24]. Such rapid decomposition results in minimal exposure of a biochemical system to PN. As an alternative approach, we have designed and constructed a biomimetic PN-generating multi-well platform capable of evolving high and sustained fluxes of PN [8]. PN-mediated covalent coupling has been proposed in aggregative protein a-synuclein [22,23,25]. Exposure of a-synuclein to PN yields aggregates significantly more stable than those formed following exposure of the protein to hydrogen peroxide $\left(\mathrm{H}_{2} \mathrm{O}_{2}\right)$. Although it has been proposed that stability of a-synuclein aggregates mediated by $\mathrm{PN}$ is most possibly due to 0,0'-dityrosine linkages ( $\mathrm{C}-\mathrm{C}$ coupling) between monomer units, $\mathrm{H}_{2} \mathrm{O}_{2}$ is also capable of imposing equivalent dimerization modalities. We suggest that additional linkages between aggregative proteins also occur through $\mathrm{C}-\mathrm{O}$ linkages between nitrated tyrosine residues in the presence of PN. Comparable bond enthalpies $\left(\Delta \mathrm{H}^{\circ}\right)$ of $\mathrm{C}-\mathrm{C}$ and $\mathrm{C}-\mathrm{O}$ (83 and $85.5 \mathrm{~kJ} \mathrm{~mol}^{-1}$, respectively) infer similar relative stabilities of the $\mathrm{C}-\mathrm{C}$ and $\mathrm{C}-\mathrm{O}$ linkages [26]. It is quite possible that at sites of chronic inflammation, an additional (and unique) PN-mediated $\mathrm{C}-\mathrm{O}$ coupling of nitrated tyrosine residues could be a crosslinking modality. Such cross-linking could lead to critical dimerization and fibril formation of aggregative proteins and provide an additional chemical feature that governs the enhanced a-synuclein aggregate stability reported previously.

\section{AUTHOR CONTRIBUTIONS}

Both T.dB and P.M. conceived the presented idea. T. $d B$ and R.P. performed the experiments. T. dB. analyzed the mass spectral data. T. dB. and P. M. contributed to the final manuscript.

\section{CONFLICTS OF INTEREST}

The authors declare that they have no conflict of interest.

\section{FUNDING}

This work was supported by a grant from the National Science Foundation (DMR-1105296).

T.dB. was supported by the National Institutes of Health (NIH AI 117064-02 S1).

\section{REFERENCES}

1. Greenacre SA, Ischiropoulos H. Tyrosine nitration: localisation, quantification, consequences for protein function and signal transduction. Free Radic Res. 2001;34(6):541-81. 
2. Radi R. Nitric oxide, oxidants, and protein tyrosine nitration. Proc Nat Acad Sci U S A. 2004 Mar 23;101(12):4003-8.

3. Szabó C, Ischiropoulos H, Radi, R. Peroxynitrite: biochemistry, pathophysiology and development of therapeutics. Nat Rev Drug Discov. 2007 Aug;6(8):662-80.

4. Pacher P, Beckman JS, Liaudet L. Nitric oxide and peroxynitrite in health and disease. Physiol Rev. 2007 Jan;87(1):315-424.

5. Uppu RM, Squadrito GL, Cueto R, Pryor PA. Selecting the most appropriate source of peroxynitrite. Method Enzymol. 1996;269:285-95.

6. Radi R. Protein tyrosine nitration: biochemical mechanisms and structural basis of functional effects. Acc Chem Res. 2013 Feb;46(2):550-9. doi: 10.1021/ar300234c

7. Abello AM, Kerstjens HA, Postma DS, Bischoff R. Protein Tyrosine nitration: selectivity, physicochemical and biological consequences, denitration, and proteomics methods for the identification of tyrosine-nitrated proteins. J Proteom Res. 2009 Jul;8(7):3222-38. doi: 10.1021/pr900039c

8. deBoer TR, Resendez A, Mascharak PK. Construction of a biomimetic peroxynitrite-generating platform: A two-component system to synthesize peroxynitrite in situ under the control of light. Chembiochem. 2013 Nov 4;14(16):2106-9. doi: 10.1002/cbic.201300488

9. Reiter CD, Teng RJ, Beckman JS. Superoxide reacts with nitric oxide to nitrate tyrosine at physiological pH via peroxynitrite. J Biol Chem. 2000 Oct 20; 275(42):32460-6.

10. Goldstein S, Czapski G, Lind J, Merényi G. Tyrosine nitration by simultaneous generation of $\mathrm{NO}$ and $\mathrm{O}_{2} \cdot{ }^{--}$under physiological conditions. J Biol Chem. 2000 Feb 4;275(5):3031-6.

11. Pfeiffer S, Mayer B. Lack of tyrosine nitration by peroxynitrite generated at physiological pH. J Biol Chem. 1998 Oct 15;273(42):27280-5.

12. Pfeiffer S, Schmidt K, Mayer B. Dityrosine formation outcompetes tyrosine nitration at low steady-state concentrations of peroxynitrite, Implications for tyrosine modification by nitric oxide/superoxide in vivo. J Biol Chem. 2000 Mar 3;275(9):6346-52.

13. deBoer TR, Palomino RI, Idiga SO, Millhauser GL, Mascharak PK. Tyrosine nitration in peptide by peroxynitrite generated in situ in a light-controlled platform: Effects of pH and thiols. J Inorg Biochem. 2014 Sep;138:24-30. doi: 10.1016/j.jinorgbio.2014.04.018

14. Griffiths-Jones SR, Maynard AJ, Searle MS. Dissecting the stability of a beta-hairpin peptide that folds in water: NMR and molecular dynamics of the beta-turn and beta-strand contributions to folding. J Mol Biol. 1999 Oct 8;292(5):1051-69.

15. Nijegorodov NI, Downey WS, Danailov MB. Systematic investigation of absorption, fluorescence and laser properties of some $\mathrm{p}$ - and $\mathrm{m}$ oligophenylenes. Spectrochim Acta A Mol Biomol Spectrosc. 2000 Mar;56(4): 783-95.

16. Momicchioli F, Mruni MC, Baraldi I. Fluorescence and absorption spectra of polyphenyls: Theoretical study on the band shape. J Phys Chem. 1972;76(26): 3983-90. doi: 10.1021/j100670a017 
17. Harms GS, Pauls SW, Hedstron JF, Johnson CK. Fluorescence and rotational dynamics of dityrosine. J Fluoresc. 1997 Dec;7(4):283-92.

18. DiMarco T, Giulivi C. Current analytical methods for the detection of dityrosine a biomarker of oxidative stress, in biological samples. Mass Spectrum Rev. 2007 Jan-Feb;26(1):108-20.

19. Erickhoff H, Jung G, Rieker A. Oxidative phenol coupling-tyrosine dimers and libraries containing tyrosyl peptide dimers. Tetrahedron. 2001;57(2): 353-64.

20. March J. Advances in Organic Chemistry: Reactions, Mechanisms and Structures. New York (US): Wiley Interscience; 1992.

21. Bunnett JF, Zahler RE. Aromatic nucleophilic substitution reactions. Chem Rev. 1951;49(2):273-412.

22. Paxinou E, Chen Q, Weisse M, Giasson BI, Norris EH, Rueter SM, et al. Induction of alpha-synuclein aggregation by intracellular nitrative insult. J Neurosci. 2001;21(20):8053-61.

23. Takakashi T, Yamashita H, Nakamura T, Nagano Y, Nakamura Y, Nakamura S. Tyrosine 125 of alpha-synuclein plays a critical role for dimerization following nitrative stress. Brain Res. 2002 May 31;938(1-2):73-80.

24. Koppenol WH, Kissner R, Beckman JS. Syntheses of peroxynitrite: to go with the flow or on solid grounds? Methods Enzymol. 1996;269:296-302.

25. Giasson BI, Duda JE, Murray IV, Chen Q, Souza JM, Hurtig HI, et al. Oxidative damage linked to neurodegeneration by selective alpha-synuclein nitration in synucleinopathy lesions. Science. 2000 Nov 3;290(5493):985-9.

26. Sanderson RT. Chemical bonds and bonds energy. New York (US): Academic Press Inc; 1976.

How to cite this article:

deBoer TR, Palomino RI, Mascharak PK. Peroxynitrite-Mediated Dimerization of 3-Nitrotyrosine: Unique Chemistry along the Spectrum of Peroxynitrite-Mediated Nitration of Tyrosine. Med One. 2019;4:e190003. https://doi.org/10.20 $\underline{900 / m o .20190003}$ 